Kiros Gebrearegawi Kebedow - Johan Oppen*

\title{
INCLUDING CONTAINERS WITH DANGEROUS GOODS IN THE CARGO MIX PROBLEM FOR CONTAINER VESSEL STOWAGE
}

The Cargo Mix Problem (CMP) chooses and distributes types of containers to load into bay subsections of a container vessel. In this paper, we extend existing Mixed Integer Programming models for the CMP by considering containers with dangerous goods. We show that our model can be optimally solved in reasonable time using standard software.

Keywords: integer programming, container stowage, Cargo Mix Problem, dangerous goods

\section{Introduction}

Maritime transportation has been, and still remains, the backbone of global trade. The introduction of containers in the maritime transportation have played an important role in modernization of the industry. The majority of containers is transported by container ships, which are specifically designed to carry containers. These ships are owned by different shipping companies. Except during the 2009 world economic crisis, the demand for sea transport has been increasing. However, the demand for efficient and cheap transportation and a fierce competition have driven shipping rates down. So, shipping companies are forced to utilize their vessels as efficiently as possible. Theoretically, the shipping companies know the nominal intake capacity of their container ships. The nominal intake capacity cannot be reached, unless the stability of the container vessel is perfect. This is a daily problem for a stowage coordinator. Stowage coordinators are the planners of the cargo, and have to find a load configuration (stowage plan) which not only suits the current cargo to be loaded, but also guarantees that the vessel can be utilized to its maximum in future ports. However, the ship size and available cargo mixes in different ports makes this work difficult.

The focus of this paper is the Cargo Mix Problem (CMP), which determines the cargo mix needed for a vessel to maximize its utilization on a given service. Differing from stowage planning, where a list of pre-selected containers must be stowed on the vessel, the Cargo Mix Problem aims at selecting the number of containers of each type that should be loaded on a vessel to maximize its intake. Moreover, standard stowage planning approaches only consider the current port, whereas the Cargo Mix Problem considers a cyclic service with multiple ports. The problem was introduced in the PhD thesis by Delgado [1] (in this work, the problem is referred to as the Container Composition Problem) and the paper by Christensen et al. [2]. The models presented in these works, however, did not take IMO containers into consideration.
The main contribution of our paper is that we include containers with dangerous goods, so-called IMO containers (IMO - the International Maritime Organization) in our model. We have not been able to find other research on the Cargo Mix Problem dealing with IMO containers.

The remainder of the paper is organized as follows: in Section 2 we provide a description of the Cargo Mix Problem. Section 3 gives a brief literature review. Our mathematical model is presented in Section 4, while we present computational results in Section 5. Finally, Section 6 concludes the paper.

\section{Problem description}

The Cargo Mix Problem requires understanding of the container ship architecture, and the shipping industry as a whole. Liner shipping companies transport containers between ports on a fixed cyclic schedule. A container is a metal box in which goods can be stored. The most commonly used container heights are 8'6" and 9'6", and lengths are 20', 40', and 45'. A 9'6" container is called a high-cube container. High-cube 20' containers are rare and we assume that they do not exist when modeling the Cargo Mix Problem. Reefer containers are containers which should be kept cool and must be supplied with electricity. Containers carrying dangerous goods are referred to as IMO containers and should follow the respective segregation principles.

The longitudinal view of a container ship (container vessel) is shown in Figure 1. A container ship is partitioned into bays. Each bay is also partitioned into on deck and below deck parts using hatch covers which are metallic, flat, water proof structures which allow containers to be placed on top of them, and which can be removed during loading/unloading containers into/from the below deck part of the vessel. Furthermore, the below deck part of the ship is physically divided into several cargo holds by upright walls within the hull of the ship called bulkheads, which are indicated by the bold vertical lines in Figure 1 .

Container ship capacity is measured in TEU. Both the on-deck and below deck parts of the vessel are partitioned into

\footnotetext{
* ${ }^{1}$ Kiros Gebrearegawi Kebedow, ${ }^{2}$ Johan Oppen

${ }^{1}$ School of Mathematical and Statistical Sciences, Hawassa University, Ethiopia

${ }^{2}$ Molde University College, Specialized University in Logistics, Norway

E-mail: Johan.Oppen@hiMolde.no
} 


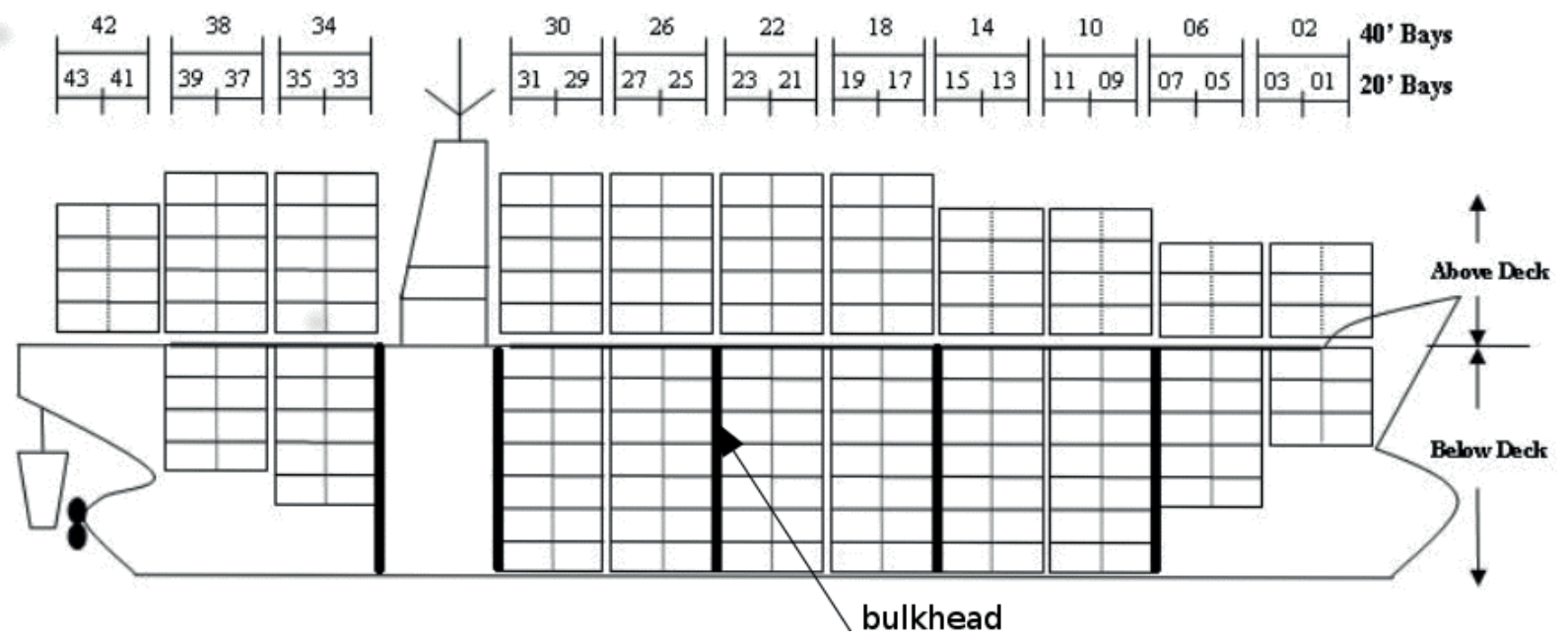

Figure 1 The longitudinal view of a container ship

The numbering of TEU and FEU bays are shown at the top [3]
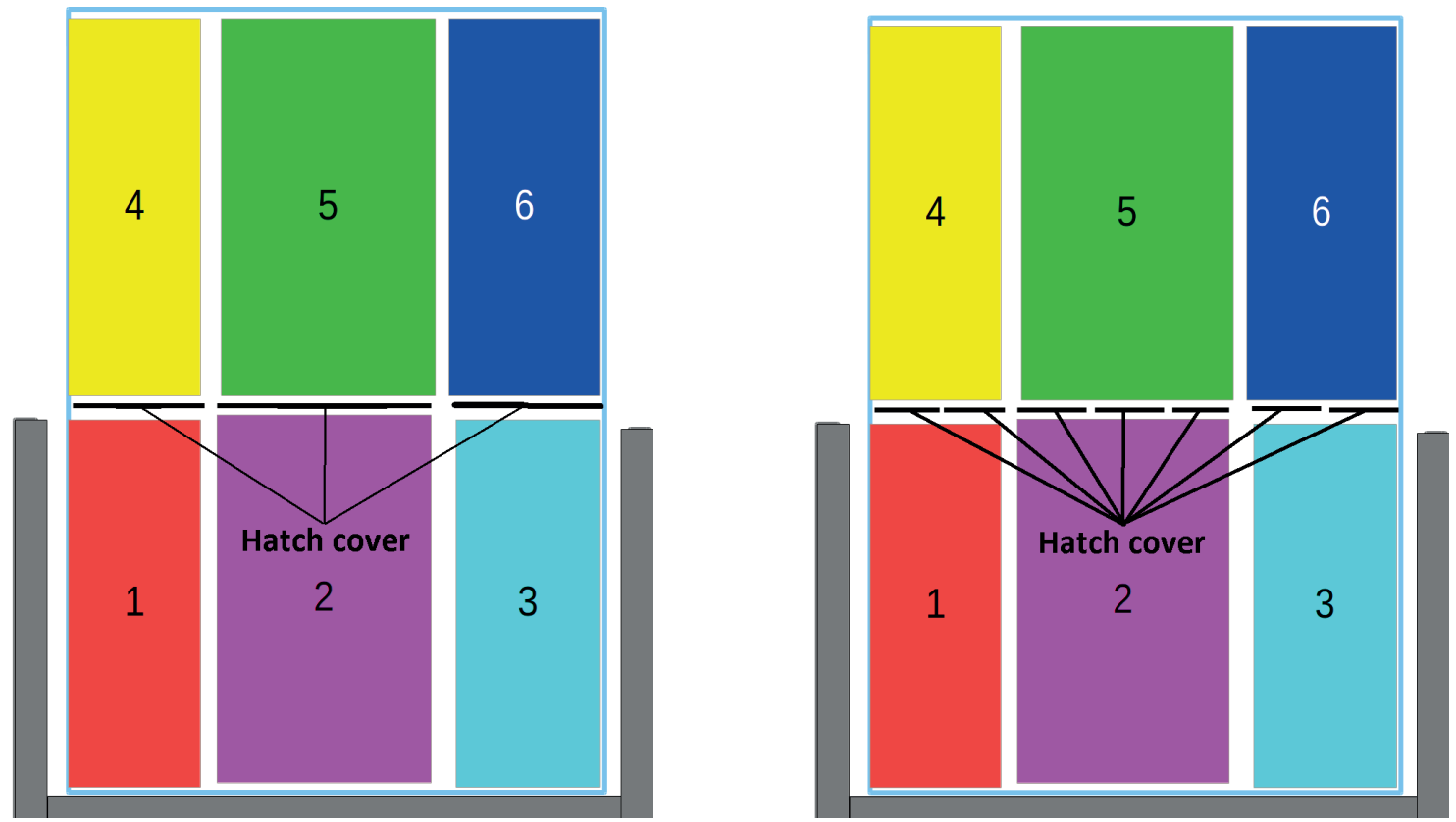

Figure 2 Locations in a bay with three (left) and seven (right) hatch covers

cells which contain two Twenty foot Equivalent Unit (TEU) or a single Forty foot Equivalent Unit (FEU) containers each. The cells are divided into two slots, a fore and an aft slot. A slot is described by three parameters called bay, row, and tier.

Most cells can hold one $40^{\prime}$ or $45^{\prime}$ container, or two 20' containers. $45^{\prime}$ containers can only be loaded in cells meant for such containers or on the upper tier (on-deck) of an FEU bay, and some cells may be restricted to either 20' or 40' containers. Due to the physical layout of the vessel, there exist odd cells that hold only one 20' container.

Containers stowed in a row form a stack, which is one container wide, and is composed of two TEU bays and a single FEU bay. A location is a bay section, which consists of a set of stacks that are either on or below deck. The stacks are adjacent, and they coincide with the same hatch cover for bays with three hatch covers, or they coincide with two or three adjacent hatch covers for bays with seven hatch covers, as depicted in Figure 2.
This definition of locations is different from the definitions in [2, 4], and we handle the problem according to the definition given here. Any location has a maximum TEU capacity, a maximum reefer container capacity, maximum capacities for different types of IMO containers, and weight limits.

Containers on a container ship are stowed one on top of the other in vertical stacks. As a result, a common situation is that, in the current port, a container with a downstream port as port of destination (POD) must be unloaded and reloaded in the current port in order to access the container below it, which has the current port as POD. This stowage configuration is called overstowage, and costs both time and money for shipping lines. Two types of over-stowage are normally considered: when a container is unloaded, the containers above it in the same stack must be unloaded first. This situation is referred to as over-stowage within location. If the container is stowed below a hatch, all containers 


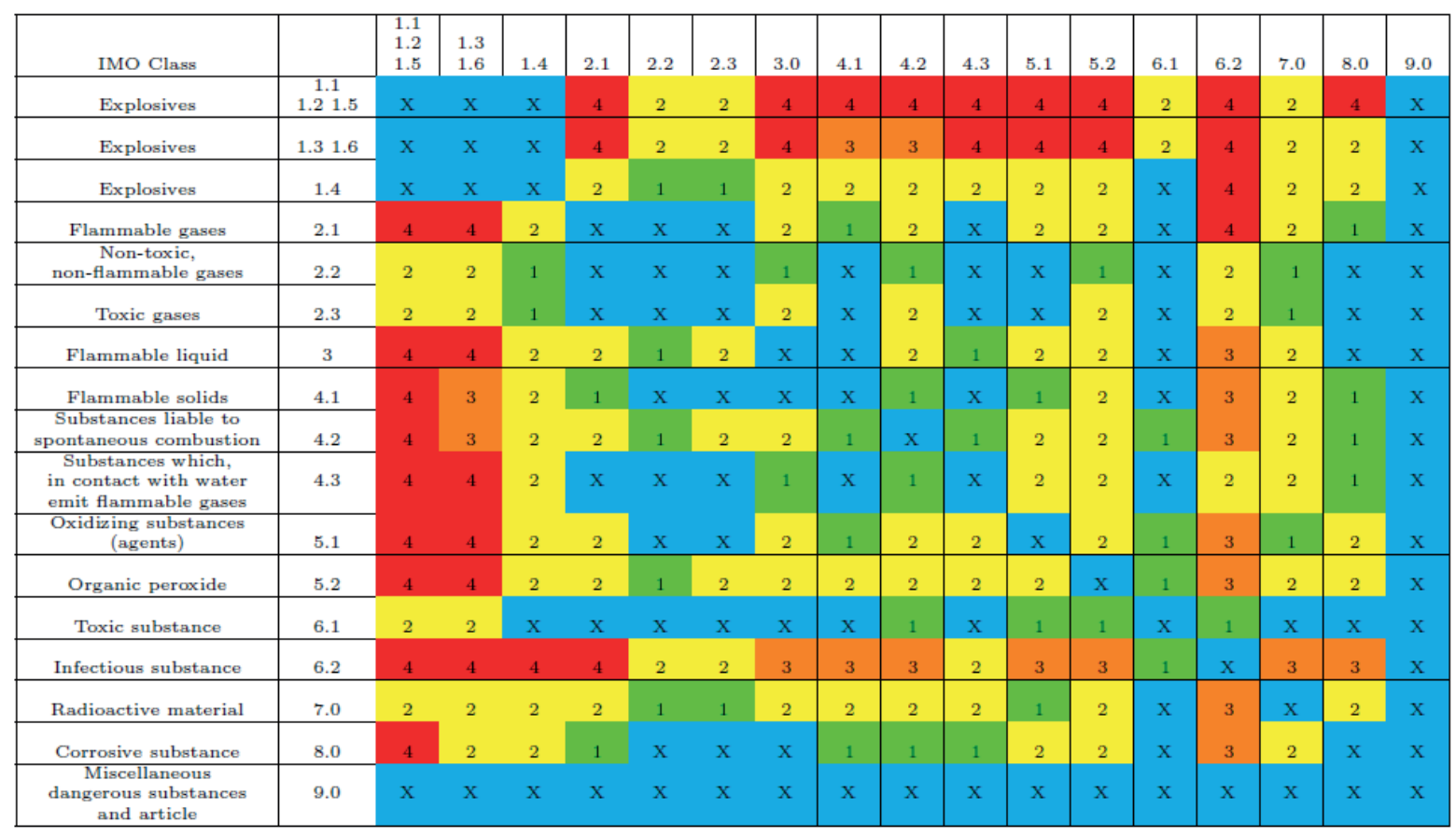

Figure 3 Segregation table, adopted from [7]

above this hatch must also be unloaded in order to open the hatch; this is called hatch over-stowage.

When a container ship is ready to leave a port it must be declared seaworthy, which means that all loaded items, i.e., cargo, ballast water, fuel, etc., must be distributed along the vessel such that its stability is acceptable, all stress forces are within limits and the draft, trim and metacentric height of the ship are also within limits. We direct interested readers to [4], [5, 6] for a more detailed description of how vessel stability is computed and modelled. The constraints related to stability in this paper are similar to those in [6].

\subsection{IMO classes and stowage rules}

According to the International Maritime Dangerous Goods Code (IMDG Code), there are nine classes of dangerous goods, some of these are divided into subclasses, currently making up a total of 17 classes. Detailed information can be found in [7]. Due to their properties, many of these substances are incompatible to each other, and thus a minimum distance has to be kept between them. For this purpose, the IMDG Code provides a number of segregation rules as indicated in Figure 3.

As shown in Figure 3, there exist four specific segregation principles that must be followed for the stowage of dangerous goods, each of them giving detailed rules for how to separate pairs of containers holding incompatible goods: 1) Away from, 2) Separated from, 3) Separated by a complete compartment from, and 4) Separated longitudinally by an intervening complete compartment or hold from.

\section{Principle 1) Away from}

Principle 1) only affects the stowing of open top containers, which are not included in this paper, thus only principles $2-4$ are considered here. The cells marked ' $\mathrm{X}$ ' in Figure 3 refer to combinations of goods where the concrete substances will lead to a certain principle (1, 2, 3 or 4$)$ to be applied.

\section{Principle 2) Separated from}

This principle means that the containers cannot be placed in the same stack (row), unless separated by a deck, while they can be stowed horizontally (in both longitudinal and transversal directions) separated by one container space. If there is a bulkhead between them, one container space is not necessary. For instance, given two incompatible IMO containers stowed according to principle 2 , if one container is stowed in bay 15 , row 09 , tier 10 , the other can be stowed in bay 17 , row 09 , tier 10 , as illustrated in Figure 4.

\section{Principle 3) Separated by a complete compartment from}

This principle means that two containers on deck cannot be placed in the same stack, while they can be stowed longitudinally separated by one container space and transversally separated by two container spaces. For example, given two incompatible IMO containers stowed according to principle 3 , if one container is stowed in bay 19 , row 03 , tier 88 , the other cannot be stowed in on-deck locations of rows $02,01,03,05$, or 07 of bays 17,19 or 21 as illustrated in Figure 4. Below deck, two containers stowed according to principle 3 cannot be placed in the same stack, horizontally they must be separated by a bulkhead. For instance, given two incompatible IMO containers stowed according to principle 3 , if one container is put below deck in any row of bay 19 , then the other cannot be put in any below deck locations belonging to bays 17, 19, 21 or 23 as illustrated in Figure 4. Note that there is a bulkhead between bay 14 and bay 18 . 


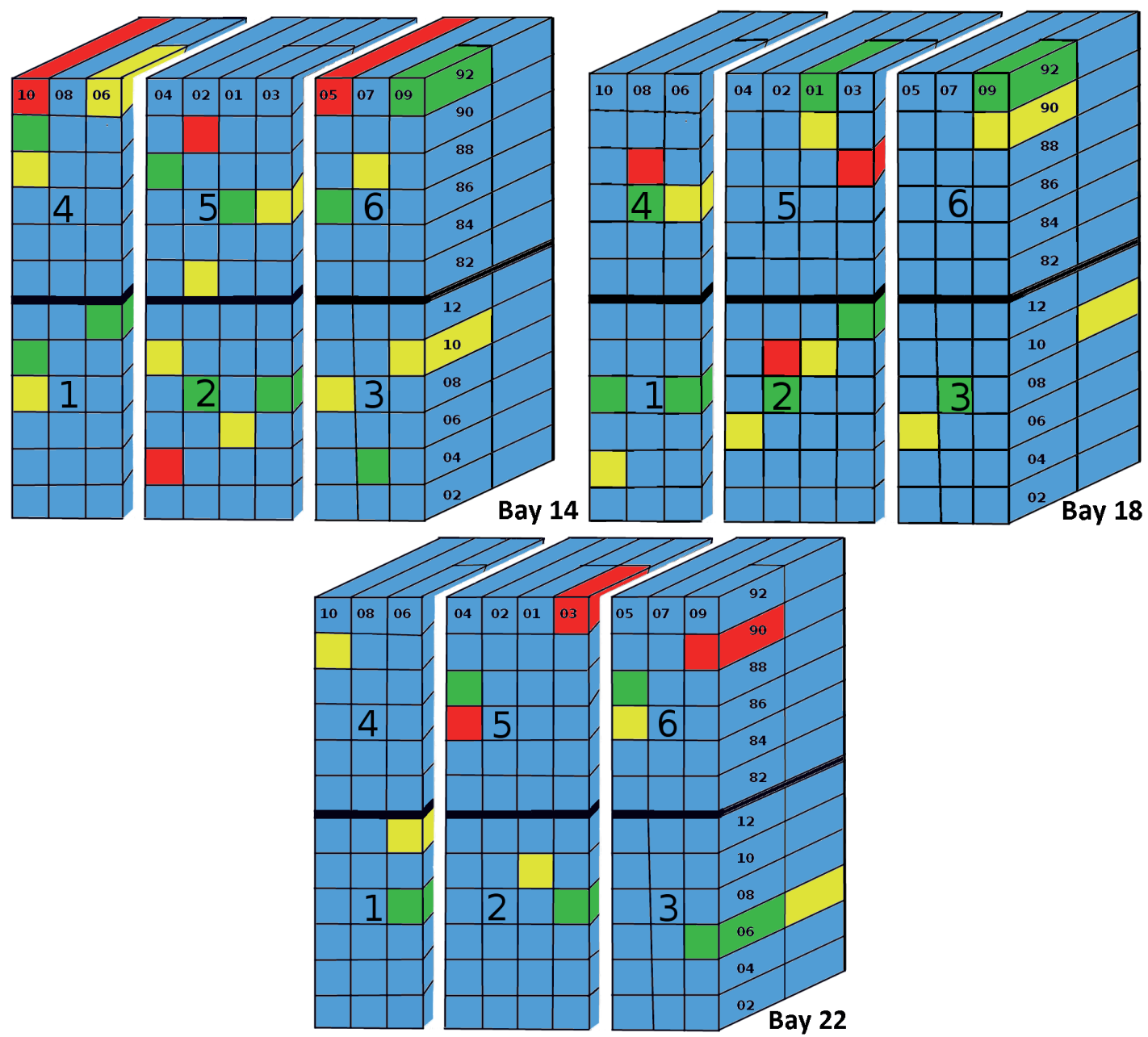

Figure 4 A container stowage configuration of two different incompatible groups of IMO containers following principle 2 (one group in yellow and the other group in green) and one incompatible group of IMO containers following principle 3 (in red) in three adjacent even bays. The setup is based on Figure 1, thus there is a bulkhead between bay 14 and bay 18

Principle 4) Separated longitudinally by an intervening complete compartment or hold from

This principle means that in on-deck locations, two containers cannot be placed in the same stack, longitudinally they require a minimum of $24 \mathrm{~m}$ (four 20' containers spaces ${ }^{1}$ ) separation, including a complete bay. Incompatible IMO containers stowed according to principle 4 in below deck locations in addition require a bulkhead separation. For example, given two incompatible IMO containers stowed according to principle 4 , if one container is stowed in any location in bay 19, the other cannot be stowed in any location (both on-deck and below deck) of bay 13, 15, $17,21,23$, or 25 . The separation principles described above are summarized in Table 1, which is taken from [8].

\subsection{Our version of the Cargo Mix Problem}

In this paper, we focus on the Cargo Mix Problem. Our model is based on the mixed integer programming models presented by Christensen et al. [2] and Ambrosino et al. [6]. Christensen et al. [2] consider 20' dry and reefer containers, 40' dry and reefer containers both normal height and high-cube. A block stowage requirement is strictly enforced in their Cargo Mix Problem, thus the containers in each location must have the same discharge port. The model presented in Ambrosino et al. [6] is for the Multi Port Master Bay Planning Problem (MP-MBPP). Even though these two problems are different, the constraints regarding with stability are the same for both problems. Ambrosino et al. [6] considers 20' and 40' dry and reefer containers with three weight classes.

Our version of the Cargo Mix Problem extends these models by including 20' and 40', reefer and IMO containers as discussed above with three weight classes, and by splitting the locations as outlined in Figure 2. This definition of locations helps us to handle hatch over-stowage in a more realistic way, as there is no need to remove containers from more than one hatch cover to get access to a given below deck container for container ships with three hatch covers in each bay and there is no need to remove containers from more than three hatch covers to get access to a given below deck container for container ships with seven hatch covers in each bay. A feasible solution for the Cargo Mix Problem must then satisfy the following rules.

1 The open space between two consecutive even bays is $3 \mathrm{~m}$. 
Table 1 Separation principles

\begin{tabular}{|c|c|c|c|c|}
\hline \multirow[t]{2}{*}{ Principle } & \multirow[t]{2}{*}{ Vertical } & & \multicolumn{2}{|c|}{ Horizontal } \\
\hline & & & On deck & Below deck \\
\hline \multirow[t]{2}{*}{1} & \multirow[t]{2}{*}{ One on top of another allowed } & Fore and aft & No restrictions & No restrictions \\
\hline & & Athwardship & No restrictions & No restrictions \\
\hline \multirow[t]{2}{*}{2} & \multirow{2}{*}{$\begin{array}{l}\text { Not in the same vertical line } \\
\text { unless separated by deck }\end{array}$} & Fore and aft & One container space & One container space \\
\hline & & Athwardship & One container space & One container space \\
\hline \multirow[t]{2}{*}{3} & \multirow{2}{*}{$\begin{array}{l}\text { Not in the same vertical line } \\
\text { unless separated by deck }\end{array}$} & Fore and aft & One container space & One bulkhead \\
\hline & & Athwardship & Two container spaces & One bulkhead \\
\hline \multirow[t]{2}{*}{4} & Not allowed & Fore and aft & $\begin{array}{l}\text { Minimum horizontal } \\
\text { distance of } 24 \mathrm{~m}\end{array}$ & $\begin{array}{l}\text { One bulkhead and minimum horizontal } \\
\text { distance of } 24 \mathrm{~m} \text {, at least } 6 \mathrm{~m} \text { from bulkhead }\end{array}$ \\
\hline & & Athwardship & Not allowed & Not allowed \\
\hline
\end{tabular}

R1: For each location and each port, the number of containers of length $20^{\prime}$ and $40^{\prime}$ must be within the TEU and FEU capacity limits of the location, respectively.

R2: For each location and each port, the number of reefer containers must be within the reefer capacity limit of the location.

R3: For each port, the numbers and positions of incompatible IMO2, IMO3 and IMO4 containers must be according to the separation rules given in Table 1.

R4: For each location and each port, the total weight of containers must be within the limits of the location.

R5: For each port, the transversal, and longitudinal stability must be secured when loading is completed.

The objective function of the Cargo Mix Problem is to maximize the weighted sum of stowed containers based on the group value of their type and length, and to minimize the weighted sum of the costs of hatch over-stowage, the makespan of the cranes along the trip, and stowage of non-reefer containers in reefer slots.

The mathematical formulation and its description in Section 4.2 gives a more precise and formal description of our version of the Cargo Mix Problem.

\section{Literature review}

The number of publications on the Cargo Mix Problem is limited. The earliest formal description was presented in the $\mathrm{PhD}$ thesis by Delgado [1], where a mixed integer programming model was presented. The author considered standard and reefer containers of length $20^{\prime}$ and $40^{\prime}$. A decomposition approach, similar to stowage planning work in [4], was applied to achieve scalability. Christensen et al. [2] consider 20' dry and reefer containers, 40 ' dry and reefer containers of both normal and highcube height. The block stowage requirement is strictly enforced in their Cargo Mix Problem, thus the containers in each location must have the same discharge port. The authors developed a matheuristic to solve the problem. The method combines a 3-phase decomposition with variable fixing and heuristic assignments. The method finds high-quality solutions in seconds, and they also claim that it can scale to industrial size instances. However, their model and solution method do not consider IMO containers.
Since the literature on the Cargo Mix Problems is scarce, we also consider literature related to stowage planning, as the Cargo Mix Problem can be viewed as a generalization of other stowage planning problems. Literature on stowage planning can be divided into two main categories: single phase and multi-phase approaches. Single phase approaches represent the stowage planning problem in a single optimization model, whereas multiphase approaches decompose the problem into two or more phases.

Within the category of single phase approaches, integer programming models have been developed by Ambrosino et al. [6, 9-11] and Li et al. [12]. The binary integer programming model in [9] considers 20' and 40' standard containers with three weight classes. Over-stowage is modeled as constraints rather than as part of the objective, and containers with special requirements, such as reefer and IMO containers, are not included. The model considers only the current port, and the objective is to minimize berthing time. Li et al. [12] proposes a binary integer programming model for the multi-port stowage planning problem, aimed to determine the exact location of each container. Similar to [9], only standard containers of length 20' and 40' are considered. This work, however, does consider over-stowage as part of the objective, but does not consider weight limitations for individual containers. The objective minimizes re-handles and maximizes the stowage space utilization. The authors solve the model for different instances of a small vessel of 800 TEUs capacity. Ambrosino et al. [10] presents a mixed integer programming model for finding stowage plans for each port visited by the ship by taking into account the hatch covers and the irregular keel of a container ship, while minimizing the total berthing time, the number of unloaded containers, and over-stowage. Similar to [9, 12], only standard containers of length $20^{\prime}$ and $40^{\prime}$ are modeled, and the model is tested only with small instances. Ding and Chou [13] developed a heuristic algorithm which can generate stowage plans with a reasonable number of shifts (over-stowage) for the stowage planning problem. They handle the transversal and longitudinal stabilities similar to [6, 9-12]. Their algorithm can make a stowage plan based on the loading information of current port only, and also considers only 20' standard containers.

Multi-phase or decomposition approaches are commonly applied to solve stowage planning problems. The earliest decomposition approach that presented promising results was the work of Wilson and Roach [14] and Wilson et al. [15], where 
the block based decomposition was introduced. In these works, a methodology for generating a stowage plan for a container ship on a multi-port journey is presented by decomposing the decision process into two planning phases: a strategic (Master Bay Planning) phase and a tactical (Slot Planning) phase. The strategic objective function includes minimizing over-stowage, imbalanced crane work, the cargo space occupied by each destination, and the cargo block (the set of stacks in a bay section i.e., location) occupied by containers.

Ambrosino et al. [11] introduce two mixed integer programming models for the MP-MBPP, dealing with practical and operational aspects of the problem: minimizing unmet demand, crane imbalance, and number of re-handles. Similar to [9-10, 12], only standard containers of length $20^{\prime}$ and $40^{\prime}$ are modeled. To solve the problem, the authors propose two different heuristic approaches based on the solution of relaxations, where all integer variables are relaxed to real values, whereas the binary variables remain constrained to $\{0,1\}$. These heuristics are tested using real life instances, and the authors claim that the models are applicable in real operations, even though the models do not consider containers with special requirements such as reefer and IMO. Ambrosino et al. [6] presents a new mixed integer programming model for the MP-MBPP that takes into account standard, reefer and open top containers of lengths $20^{\prime}$ and 40 , and hatch cover positions in the ships. The objective is to minimize the number of re-handles and imbalanced crane work. Unlike [9-10, 12], Ambrosino et al. [6, 11] assigns containers to the bays of the container ship i.e. only dealing with the Master Bay Planning problem. In the models presented in [6, 9-12], the constraints dealing with transversal and longitudinal stability are constructed by forcing the weight on the right side of the ship to be equal to the weight on the left side of the ship within given tolerances, and the weight on the stern of the ship to be equal to the weight on the bow of the ship within given tolerances. In addition, the constraints dealing with vertical stability and metacentric height are constructed by forcing containers to be stowed in ascending order of weight from the bottom to the top in the same stack.

Kang and Kim [16] present a two phase decomposition approach of the stowage planning problem: in the first phase they assign groups of standard containers of length $40^{\prime}$ to the locations of the ship, in the second phase they determine the loading sequence of containers in each location aimed at minimizing the total berthing time at each port along the route. The constraints in the first phase are dealing with the stability of the ship, all containers in the load list must be loaded, and the containers loaded in a location must be within the capacity of the location. The authors propose heuristic methods to solve the problem. A decomposition of the multi-port stowage planning problem into two phases is also presented by Wei-Ying et al. [17], aimed at minimizing over-stowage and the number of bays occupied by containers at each port. In the first phase, containers are aggregated into homogeneous groups based on their type, length, height, weight and port of destination, the groups are then assigned to bays. This phase is solved using a bin packing algorithm where bays are regarded as bins, the number of slots in each bay are taken as capacities of bins, and containers with different characteristics (homogeneous container groups) are treated as items to pack. Pacino et al. [4] solve the stowage planning problem by decomposing it hierarchically into two phases: the Multi-Port Master Bay Planning Problem and the Slot Planning Problem. In the MP-MBPP, an integer programming model that assigns groups of different container types (standard light, standard heavy, reefer light and reefer heavy) to locations of the container ship is presented. This model is then solved after relaxing some of the variables. The Slot Planning Problem is solved by a constraint programming and local search procedure. Pacino et al. [4] develop a linear integer programming model with ballast tanks which leads to variable displacement for the MP-MBPP. They present a linearization approach for the center of gravity and hydrostatic data tables of the vessel, to formulate stability and stress constraints that can handle variable displacement. The objective is to minimize the changes in ballast water.

In Azevedo et al. [18], the problem is modelled as a 3D-stochastic stowage planning problem, and the authors propose a three-level solution to minimize unnecessary container movements and ship instability, but their assumptions are probably not fully applicable in a real world situation.

Parreno et al. [19] develop a binary programming model and a GRASP algorithm to solve the Slot Planning Problem where handling of IMO containers is included. To our knowledge, this is the only paper in the literature dealing with IMO containers.

\section{A mathematical model for the Cargo Mix Problem}

The Cargo Mix Problem (CMP) chooses and distributes types of containers to load into locations of a container vessel. We now introduce our mixed integer programming model formulated to solve the CMP.

\subsection{Notation}

In this subsection, we present the notation used in the model. Sets are listed in Table 2, constants are given in Table 3, and variables are listed in Table 4.

Containers are divided into groups by length (20' or 40'), weight classes (heavy $(\mathrm{H})$, Medium(M) or Light (L)), type of container (S, R, IMOC1, IMOC2, IMOC3, ... IMOC $|\mathrm{D}|$ ), this grouping is used for different purposes in the model. IMO containers are split into different IMO classes $(1,2,3, \ldots,|\mathrm{D}|)$. As shown in Figure 3, there are currently 17 classes of dangerous goods. We consider the containers containing one class of dangerous goods as one IMO container type. The IMO containers of each class are incompatible with other IMO containers by respecting one of the segregation principles, so the incompatible containers must be stored according to the stowing rules for the given principle.

We include only FEU bays in the set $B$, as there is no need to keep track of the fore and aft parts of each bay in the Cargo Mix Problem.

Locations are also grouped based on different properties, the rules for separating IMO containers make it necessary to 
Table 2 Sets

\begin{tabular}{|c|c|}
\hline Notation & Explanation \\
\hline$W$ & weight classes of containers (light(l),medium (m),heavy (h)) \\
\hline$C_{L}$ & lengths of containers $\left(20^{\circ}, 40^{\circ}\right)$ \\
\hline$D$ & classes of dangerous goods \\
\hline$S$ & segregation principles $\{2,3,4\}$ \\
\hline$T$ & container types (standard, reefer, imoc, imoc $_{2}, \ldots .$, imoc $_{|\mathrm{d}|}$ ) \\
\hline$T_{R}$ & reefer container types (reefer ) \\
\hline$T_{d}$ & container types for dangerous goods of class $d\left(I M O C_{d}\right)$ \\
\hline$T_{d}^{j}$ & container types following segregation principle $j$ with respect to containers of type $T_{d}$ \\
\hline$H$ & bulkheads \\
\hline$H^{A D J}$ & pairs of adjacent bulkheads $\{(1,2),(2,3), \ldots,(|H|-1,|H|)\}$ \\
\hline$B$ & even bays $\{2,6,10, \ldots\}$ \\
\hline$B^{E X}$ & $\begin{array}{l}\text { pairs of exclusive adjacent bays, each bay is included in two consecutive pairs of bays } \\
\{(2,6),(10,14), \ldots\}\end{array}$ \\
\hline$B^{I N}$ & $\begin{array}{l}\text { pairs of inclusive adjacent bays, each bay is included in only one pair of bays } \\
\{(2,6),(6,10), \ldots\}\end{array}$ \\
\hline$V$ & set of positions for locations $\{W S, C, P S\}$ \\
\hline$L$ & locations \\
\hline$L^{o}$ & on-deck locations \\
\hline$L^{U}$ & below deck locations \\
\hline$L_{h h^{\prime}}^{U}$ & below deck location below on-deck location $l$ \\
\hline$L_{b}^{E X}$ & water side locations (all locations to water side of a ship) \\
\hline$L_{b}^{I N}$ & port side locations (all locations to the port side of a ship) \\
\hline$L^{A}$ & aft locations (all locations to aft part of the ship from its center) \\
\hline$L^{F}$ & fore locations from its center (all locations to fore part of the ship) \\
\hline$L_{h h^{\prime}}^{U}$ & below deck locations between two adjacent bulkheads $h$ and $h^{\prime}$ \\
\hline$L_{b}^{E X}$ & locations in pair of exclusive adjacent bays \\
\hline$L_{b}^{I N}$ & locations in pair of inclusive adjacent bays \\
\hline$P$ & ports to be visited by the vessel \\
\hline$R$ & transports, represented by a load-discharge port pair $\left(p_{i}, p_{j}\right)$ \\
\hline$R_{p}$ & transports with containers on the vessel at departure from port $p$ \\
\hline$R_{b}^{A}$ & transports loaded or unloaded in port $p$ \\
\hline$R_{p}^{O V}$ & transports which over-stow containers to load or unload in port $p$ \\
\hline
\end{tabular}

keep track of below deck and on-deck locations and locations in adjacent bays.

A transport is a pair of load-discharge ports $\left(p_{i}, p_{j}\right)$ where containers are transported from port $p_{i}$ to port $p_{j}$, and port $p_{i}$ is visited before port $p_{i}$.

The $x^{a}$ variables are the decision variables of the problem, assigning the number of $20^{\prime}$ and $40^{\prime}$ ' containers of each type to be stowed in each location of the container ship during each transport. The binary variables $\delta$ indicate hatch over-stowage. The variables $y^{O}$ calculate the amount of hatch over-stowage. The variables $y^{T}$ and $y^{R}$ calculate crane makespan and reduced reefer container capacity, respectively.

\subsection{Formulation}

The mixed integer programming model is formulated as follows:

$\max \sum_{r \in R} \sum_{t \in T} \sum_{w \in W} \sum_{\alpha \in C_{1}} V_{r}^{\alpha w t} \sum_{l \in L} x_{r l}^{\alpha w t}-$
$-\sum_{p \in P} \sum_{l \in L}\left(C^{O} y_{p l}^{O}+C^{R} y_{p l}^{R}\right)-\sum_{p \in P} C^{T} y_{p}^{T}$

subject to

$\sum_{r \in R_{p}} \sum_{t \in T} \sum_{e \in W} \sum_{\alpha \in C_{1}} \Lambda_{\alpha} x_{r l}^{\alpha \omega t} \leq C_{p l}^{T}, p \in P, l \in L$

$\sum_{r \in R_{p}} \sum_{t \in T} \sum_{w \in W} \sum_{\alpha \in C 1} \Lambda_{\alpha} x_{r l}^{\alpha w t} \leq C_{p l}^{R}, p \in P, l \in L$

$\sum_{r \in R_{p}} \sum_{t \in T} \sum_{w \in W} \sum_{\alpha \in C 1} x_{r l}^{\alpha w t} \leq \phi_{p l}^{d} M, p \in P, l \in L, d \in D$ 
Table 3 Constants

\begin{tabular}{|c|c|}
\hline Notation & Explanation \\
\hline$C_{p l}^{T}$ & TEU capacity of location $l$ in port $p$ \\
\hline$C_{p l}^{R}$ & reefer container capacity of location $l$ in port $p$ \\
\hline$C_{p l}^{\alpha}$ & capacity of length $\alpha$ containers in location $l$ in port $p$ \\
\hline$C_{p l}^{j d}$ & $\begin{array}{l}\text { capacity of containers incompatible with containers in } T_{d} \text { following segregation principle } \\
j \text { in location } l \text { in port } p\end{array}$ \\
\hline$L_{r}^{\alpha t}$ & number of available containers of length $\alpha$ and type $t$ in transport $r$ \\
\hline$W_{p l}^{T}$ & maximum weight of all containers in location $l$ in port $p$ \\
\hline$W^{\alpha w}$ & average weight of length $a$ and weight class $w$ \\
\hline$Q_{T}$ & maximum cross (transversal) equilibrium \\
\hline$Q_{L}$ & maximum horizontal (longitudinal) equilibrium \\
\hline$V_{r}^{\alpha w t}$ & the value of container type $t$ length $a$, and weight class $w$ of transport $r$ \\
\hline$\Lambda_{\alpha} \in\{1,2\}$ & TEU coefficient of a container with length $a$ \\
\hline$C^{o}$ & cost of one hatch over-stowing container \\
\hline$C^{R}$ & cost of one unit reduction of reefer container capacity \\
\hline$C^{T}$ & cost of one time unit of crane makespan \\
\hline$C^{\text {Time }}$ & average crane time needed to load or unload a TEU unit \\
\hline$M$ & big number \\
\hline$M_{3}$ & sum of the TEU capacity of the locations in $L_{h h^{\prime}}^{U}$ \\
\hline$M_{4}$ & sum of the TEU capacity of the locations in $L_{b}^{I N}$ \\
\hline$M_{h h^{\prime}}$ & number of locations in $L_{h h^{\prime}}^{U}$ \\
\hline$M_{b}$ & number of locations in $L_{b}^{I N}$ \\
\hline$R_{p l}^{D}$ & number of TEU units to be discharged from location $l$ in port $p$ \\
\hline$R_{p l}^{O V}$ & number of over-stowing TEU units in location $l$ in port $p$ \\
\hline$R_{p l}^{A}$ & number of TEU units to be loaded or discharged in location $l$ in port $p$ \\
\hline
\end{tabular}

Table 4 Variables

\begin{tabular}{cl}
\hline Notation & Explanation \\
\hline$x_{r l}^{\alpha w t}$ & number of containers with length $\alpha$, weight $w$ of type $t$ stowed in location $l$ during transport $r$ \\
$\delta_{p l}$ & 1 if there are containers to load or discharge in port $p$ below on-deck location $l, 0$ otherwise \\
$\phi_{p l}^{d}$ & 1 if there are containers containing dangerous goods of class $d$ in location $l$ when the vessel leaves port $p, 0$ otherwise \\
$\lambda_{\left(h h^{\prime}\right) p}^{d}$ & $\begin{array}{l}1 \text { if there are containers incompatible with class } d \text { following segregation principle } 3 \text { in under deck locations between two adjacent } \\
\text { bulkheads } h \text { and } h \text { ' when the vessel leaves port } p, 0 \text { otherwise }\end{array}$ \\
$\varphi_{b p}^{d}$ & $\begin{array}{l}1 \text { if there are containers incompatible with class } p \text { following segregation principle } 4 \text { in locations in pair } b \text { of inclusive adjacent bays } \\
\text { when the vessel leaves port } p, 0 \text { otherwise }\end{array}$ \\
$y_{p l}^{O}$ & number of hatch over-stowed TEU units to load or discharge in location $l$ in port $p$ \\
$y_{p}^{T}$ & crane makespan in port $p$ \\
$y_{p l}^{R}$ & reduction of reefer TEU capacity in location $l$ in port $p$ \\
\hline
\end{tabular}

$\sum_{r \in R_{p}} \sum_{t \in T^{j}} \sum_{w \in W} \sum_{\alpha \in C_{1}} x_{r l}^{\alpha w t}-\left(1-\phi_{p l}^{d}\right) M \leq C_{p l}^{j d}$,

$p \in P, l \in L, d \in D, j \in S$

$\sum_{r \in R_{p}} \sum_{l \in L_{h h^{\prime}}^{U}} \sum_{t \in T_{d}^{3}} \sum_{w \in W} \sum_{\alpha \in C_{L}} x_{r l}^{\alpha w t} \leq \lambda_{\left(h h^{\prime}\right)_{p}}^{d} M_{3}$,

$p \in P, d \in D,\left(h h^{\prime}\right) \in H^{A D J}$

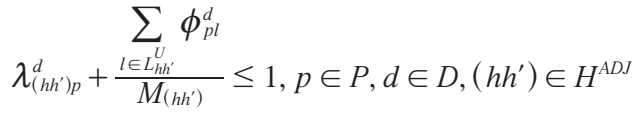

$\sum_{r \in R_{p}} \sum_{l \in L_{b}^{I N}} \sum_{t \in T_{d}^{4}} \sum_{w \in W} \sum_{\alpha \in C_{L}} x_{r l}^{\alpha w t} \leq \varphi_{b_{p}}^{d} M_{4}$,

$p \in P, d \in D, b \in B^{I N}$ 
Table 5 Proportion of container types to be loaded in the Cargo Mix Problem. The column 'Principles' indicates the principles following the IMO containers in the given scenario

\begin{tabular}{|c|c|c|c|c|c|c|c|}
\hline Scenario & ST & $\mathrm{R}$ & $\mathrm{IMOC}_{1}$ & $\mathrm{IMOC}_{2}$ & $\mathrm{IMOC}_{3}$ & $\mathrm{IMOC}_{4}$ & Principles \\
\hline $\mathrm{S}_{1}$ & 70 & 10 & 7.5 & 7.5 & 3.5 & 1.5 & $2,3,4$ \\
\hline $\mathrm{S}_{2}$ & 71.5 & 10 & 7.5 & 7.5 & 3.5 & 0 & $2,3,4$ \\
\hline $\mathrm{S}_{3}$ & 75 & 10 & 7.5 & 7.5 & 0 & 0 & 2 \\
\hline $\mathrm{S}_{4}$ & 82.5 & 10 & 7.5 & 0 & 0 & 0 & - \\
\hline $\mathrm{S}_{5}$ & 90 & 10 & 0 & 0 & 0 & 0 & - \\
\hline $\mathrm{S}_{6}$ & 100 & 0 & 0 & 0 & 0 & 0 & - \\
\hline
\end{tabular}

Table 6 Overview of instances: the columns under Vessel present ship dependent data: Loc is the total number of locations, Tot Cap is the total capacity of the ship in TEU and $R$ Cap is the reefer capacity of the ship. Port indicates the number of ports along the route. The columns under Available containers to load presents the number of available containers of lengths 20', and 40', which will be loaded at current port and downstream ports. Transports is the total number of active transports, and the two rightmost columns show the maximum and minimum number of integer (binary) variables in the model

\begin{tabular}{|c|c|c|c|c|c|c|c|c|c|c|c|}
\hline \multirow{3}{*}{ ID } & \multirow{3}{*}{ Loc } & \multicolumn{3}{|l|}{ Vessel } & \multicolumn{4}{|c|}{ Available containers to load } & \multirow{3}{*}{$\begin{array}{l}\text { Tran } \\
\text { sports }\end{array}$} & \multirow{2}{*}{\multicolumn{2}{|c|}{$\begin{array}{l}\text { No of variables } \\
\text { Integer (binary) }\end{array}$}} \\
\hline & & Tot & $\mathrm{R}$ & Port & \multicolumn{2}{|c|}{ Current port } & \multicolumn{2}{|c|}{ Downstream ports } & & & \\
\hline & & Cap & Cap & & $20{ }^{\prime}$ & $40^{\prime}$ & $20{ }^{\prime}$ & $40^{\prime}$ & & $\operatorname{Max}$ & Min \\
\hline 1 & 66 & 2376 & 250 & 6 & 800 & 800 & 1962 & 1962 & 15 & $28480(7200)$ & $6230(132)$ \\
\hline 2 & 120 & 3600 & 370 & 6 & 1018 & 1018 & 1496 & 1962 & 15 & $56546(9740)$ & $11160(360)$ \\
\hline 3 & 234 & 7800 & 800 & 6 & 2898 & 1920 & 7960 & 3984 & 15 & $91156(10408)$ & $21086(468)$ \\
\hline 4 & 300 & 10000 & 1000 & 6 & 2898 & 1920 & 7910 & 3984 & 15 & $117035(13725)$ & $27026(600)$ \\
\hline 5 & 276 & 18032 & 1680 & 6 & 4022 & 5990 & 7960 & 13868 & 15 & $116221(12627)$ & $25142(552)$ \\
\hline
\end{tabular}

$$
\begin{aligned}
& \varphi_{p}^{d}+\frac{\sum_{l \in L_{B h}^{I N}} \phi_{p l}^{d}}{M_{b}} \leq 1, p \in P, d \in D, b \in B^{I N} \\
& \sum_{r \in R_{p}} \sum_{t \in T} \sum_{w \in W} x_{r l}^{\alpha w t} \leq C_{p l}^{\alpha}, p \in P, l \in L, \alpha \in C_{L} \\
& \sum_{l \in L} \sum_{w \in W} x_{r l}^{\alpha w t} \leq L_{r}^{\alpha t}, \alpha \in C_{L}, t \in T, r \in R \\
& \sum_{r \in R_{p}} \sum_{t \in T} \sum_{w \in W} \sum_{\alpha \in C L} W^{\alpha_{w}} x_{r l}^{\alpha_{w} t} \leq W_{p l}^{T}, p \in P, l \in L \\
& \left|\sum_{r \in R_{p}} \sum_{t \in T} \sum_{w \in W} \sum_{\alpha \in C_{L}}\left(\sum_{l \in L^{W S}} W^{\alpha_{w}} x_{r l}^{\alpha_{l} t}\right)\right| \leq Q_{T} \\
& \left|\sum_{r \in R_{p}} \sum_{t \in T} \sum_{w \in W} \sum_{\alpha \in C_{L}}\left(\sum_{l \in L^{A}} W^{\alpha_{w}} x_{r l}^{\alpha_{l} t}-\sum_{l \in L^{F}} W^{\alpha_{w}} x_{r l}^{\alpha^{w} t}\right)\right| \leq Q_{L} \\
& \sum_{l^{\prime} \in L_{l}^{U}}\left(R_{p l^{\prime}}^{D}+\sum_{r \in R_{p}^{A}} \sum_{t \in T} \sum_{w \in W} \sum_{\alpha \in C_{L}} x_{r l^{\prime}}^{\alpha w t}\right) \leq M \delta_{p l}, p \in P, l \in L^{O} \\
& R_{p l}^{O V}+\sum_{r \in R_{p}^{O V}} \sum_{t \in T} \sum_{w \in W} \sum_{\alpha \in C L} \Lambda_{\alpha} x_{r l}^{\alpha w t}-M\left(1-\delta_{p l}\right) \leq y_{p l}^{O}, \\
& p \in P, l \in L^{O} \\
& C^{\text {Time }} \sum_{r \in R_{p}^{A}} \sum_{l \in L_{b}^{E X}}\left(R_{p l}^{A}+\sum_{t \in T} \sum_{w \in W} \sum_{\alpha \in C_{L}} \Lambda_{\alpha} x_{r l}^{\alpha w t}\right) \leq y_{p}^{T}, \\
& p \in P, b \in B^{E X} \\
& \sum_{r \in R_{p}} \sum_{t \in T} \sum_{w \in W} \sum_{\alpha \in C L} F_{p l}^{t} \Lambda_{\alpha} x_{r l}^{\alpha w t}-C_{p l}^{R} \leq y_{p l}^{R}, p \in P, l \in L \\
& x_{r l}^{\alpha w t} \in N \cup\{0\}, \alpha \in C_{L}, w \in W, t \in T, r \in R, l \in L \\
& \delta_{p l} \in\{0,1\}, p \in P, l \in L \\
& \varphi_{b p}^{d} \in\{0,1\}, p \in P, b \in B^{I N}, d \in D \\
& \phi_{p l}^{d} \in\{0,1\}, p \in P, l \in L, d \in D \\
& \lambda_{\left(h h^{\prime}\right) p}^{d} \in\{0,1\}, p \in P,\left(h h^{\prime}\right) \in H^{A D J}, d \in D
\end{aligned}
$$

$y_{p l}^{O} \in N \cup\{0\}, p \in P, l \in L$

$$
y_{p}^{T}, y_{p l}^{R} \geq 0, p \in P, l \in L
$$

The objective function (1) maximizes the weighted sum of stowed containers based on the group value of their type and length, minus the weighted sum of costs of hatch over-stowage, the makespan of the cranes along the trip, and stowage of non-reefer containers in reefer slots.

The constraints in (2), (3) and (5) ensure that location capacities are not violated. Constraints (2) and (3) ensure that TEU and reefer container capacities of each location in each port are respected.

Constraints (4) set the binary variables $\phi_{p l}^{d}$ to 1 if there are containers with dangerous goods of class $d$ to load, or already loaded, in port $p$ in location $l$. Constraint (5) ensures that the number of incompatible containers following principles 2 and 3 in each location (for principle 3, only on-deck locations) never exceed the given limits.

Constraints (6) set the binary variables $\lambda_{\left(h h^{\prime}\right) p}^{d}$ to 1 if there are containers incompatible with containers containing dangerous goods of class $d$ following principle 3 to load, or already loaded, in port $p$ in the under deck locations between two adjacent bulkheads $h$ and $h$ '.

Constraint set (7) ensures that incompatible containers following principle 3 in below deck locations are separated by a bulkhead.

Constraint set (8) sets the binary variables $\varphi_{b p}^{d}$ to 1 if there are containers incompatible with containers containing dangerous goods of class $d$ following principle 4 to load, or already loaded, in port $p$ in locations in pair $b$ of inclusive adjacent bays. 
Table 7 CMP results with one hour run time. The first and second columns are the instance Scenario and ID, respectively, the third column is the best found objective value. The fourth column shows the number of hatch over-stowing containers along the route. The fifth column is the run time used by the solver to find the best solution, and the last column is the optimality gap. We have used a maximum cross (transversal) equilibrium ( $\left.Q_{T}\right)$ and maximum horizontal (longitudinal) equilibrium $\left(Q_{L}\right)$ of 60 tons, which is equal to two 40' heavy containers

\begin{tabular}{|c|c|c|c|c|c|}
\hline Scen & ID & Obj $\left(10^{3}\right)$ & HOS (TEU) & Runtime (s) & Gap (\%) \\
\hline \multirow{5}{*}{$\mathrm{S}_{1}$} & 1 & 849.26 & 0 & 2990 & 0.13 \\
\hline & 2 & 1145.48 & 0 & 2400 & 0.08 \\
\hline & 3 & 2965.26 & 1 & 360 & 0.02 \\
\hline & 4 & 3067.08 & 0 & 3400 & 0.00 \\
\hline & 5 & 6788.77 & 10 & 2700 & 0.23 \\
\hline \multirow{5}{*}{$\mathrm{S}_{2}$} & 1 & 848.65 & 0 & 3500 & 0.22 \\
\hline & 2 & 1145.91 & 0 & 1500 & 0.04 \\
\hline & 3 & 2965.16 & 0 & 2070 & 0.00 \\
\hline & 4 & 3066.68 & 0 & 280 & 0.00 \\
\hline & 5 & 6790.52 & 1 & 3470 & 0.23 \\
\hline \multirow{5}{*}{$\mathrm{S}_{3}$} & 1 & 848.30 & 0 & 2680 & 0.24 \\
\hline & 2 & 1145.52 & 0 & 3180 & 0.07 \\
\hline & 3 & 2965.22 & 0 & 1430 & 0.00 \\
\hline & 4 & 3066.78 & 0 & 440 & 0.00 \\
\hline & 5 & 6801.53 & 0 & 2740 & 0.04 \\
\hline \multirow{5}{*}{$\mathrm{S}_{4}$} & 1 & 849.40 & 0 & 2680 & 0.10 \\
\hline & 2 & 1144.67 & 0 & 480 & 0.03 \\
\hline & 3 & 2964.87 & 3 & 1890 & 0.02 \\
\hline & 4 & 3066.70 & 0 & 370 & 0.00 \\
\hline & 5 & 6800.79 & 0 & 2700 & 0.06 \\
\hline \multirow{5}{*}{$\mathrm{S}_{5}$} & 1 & 850.17 & 0 & 1600 & 0.02 \\
\hline & 2 & 1144.24 & 0 & 1870 & 0.00 \\
\hline & 3 & 2965.30 & 0 & 180 & 0.00 \\
\hline & 4 & 3066.65 & 0 & 180 & 0.00 \\
\hline & 5 & 6796.20 & 0 & 2600 & 0.04 \\
\hline \multirow{5}{*}{$\mathrm{S}_{6}$} & 1 & 872.10 & 0 & 2780 & 0.00 \\
\hline & 2 & 1187.44 & 0 & 410 & 0.00 \\
\hline & 3 & 2919.98 & 0 & 2780 & 0.00 \\
\hline & 4 & 3028.38 & 0 & 65 & 0.00 \\
\hline & 5 & 6721.24 & 0 & 1350 & 0.03 \\
\hline
\end{tabular}

Constraint set (9) ensures that incompatible IMO containers following principle 4 are separated by at least two even bays longitudinally, including a complete compartment. When incompatible IMO containers following principle 4 are stowed in below deck locations, additional bulkhead separation is needed, but there are always enough bulkheads with two even bays separation.

Constraint set (10) ensures that the number of containers of each length in each location is within the location's capacity. This constraint set is quite similar to (2), but if a location has two odd cells, the constraints in (10) are needed to ensure that it is possible to load two 20' containers, but not one 40' container, in these two cells. The constraints in (11) ensure that the number of loaded containers in all transports do not exceed the number of available containers. Constraint set (12) ensures that the weight of all containers in each location is within the weight limit of the location.

The constraints (13) and (14) control the stability of the container ship in each port visited. The stability conditions are described in terms of the longitudinal and transversal equilibrium. This means that the difference of the weights of the water side and port side should be within the transversal equilibrium, and 
Table 8 CMP results with different values of $Q_{L}$ and $Q_{R}$ in one hour run time. For each pair of values for $Q_{L}$ and $Q_{R}$ the table shows the best found objective value, the optimality gap and the run time

\begin{tabular}{|c|c|c|c|c|c|c|c|c|c|c|}
\hline \multirow[t]{2}{*}{ Scen } & \multirow[t]{2}{*}{ ID } & \multicolumn{3}{|c|}{$\mathrm{Q}_{\mathrm{L}}=\mathrm{Q}_{\mathrm{T}}=30$ tons } & \multicolumn{3}{|c|}{$\mathrm{Q}_{\mathrm{L}}=\mathrm{Q}_{\mathrm{T}}=90$ tons } & \multicolumn{3}{|c|}{$\mathrm{Q}_{\mathrm{L}}=\mathrm{Q}_{\mathrm{T}}=120$ tons } \\
\hline & & $\operatorname{Obj}\left(10^{3}\right)$ & Time (s) & Gap (\%) & $\operatorname{Obj}\left(10^{3}\right)$ & Time (s) & Gap (\%) & $\operatorname{Obj}\left(10^{3}\right)$ & Time (s) & Gap (\%) \\
\hline \multirow{5}{*}{$\mathrm{S}_{1}$} & 1 & 849.71 & 1850 & 0.10 & 849.00 & 3200 & 0.16 & 849.64 & 2290 & 0.09 \\
\hline & 2 & 1146.07 & 940 & 0.03 & 1146.26 & 2920 & 0.00 & 1145.69 & 2060 & 0.06 \\
\hline & 3 & 2964.14 & 2490 & 0.06 & 2964.21 & 1840 & 0.05 & 2964.63 & 3464 & 0.04 \\
\hline & 4 & 3067.00 & 1216 & 0.00 & 3067.04 & 1449 & 0.00 & 3066.96 & 164 & 0.00 \\
\hline & 5 & 6796.09 & 2960 & 0.12 & 6801.00 & 3540 & 0.05 & 6801.75 & 2750 & 0.04 \\
\hline \multirow{5}{*}{$\mathrm{S}_{2}$} & 1 & 849.73 & 2212 & 0.06 & 850.08 & 3510 & 0.02 & 849.08 & 1380 & 0.18 \\
\hline & 2 & 1146.28 & 2370 & 0.00 & 1146.42 & 650 & 0.02 & 1146.14 & 2650 & 0.02 \\
\hline & 3 & 2964.79 & 3000 & 0.02 & 2958.83 & 2410 & 0.23 & 2956.66 & 3480 & 0.30 \\
\hline & 4 & 3066.72 & 1505 & 0.00 & 3066.70 & 2252 & 0.00 & 3066.72 & 720 & 0.00 \\
\hline & 5 & 6759.54 & 3190 & 0.66 & 6784.55 & 3400 & 0.29 & 6783.57 & 2380 & 0.30 \\
\hline \multirow{5}{*}{$\mathrm{S}_{3}$} & 1 & 849.59 & 2960 & 0.11 & 849.70 & 2190 & 0.07 & 849.32 & 3430 & 0.12 \\
\hline & 2 & 1146.28 & 2800 & 0.00 & 1146.36 & 1950 & 0.00 & 1146.28 & 1690 & 0.00 \\
\hline & 3 & 2964.79 & 2050 & 0.02 & 2965.23 & 1134 & 0.00 & 2965.34 & 1910 & 0.00 \\
\hline & 4 & 3066.72 & 190 & 0.00 & 3066.67 & 526 & 0.00 & 3066.63 & 300 & 0.00 \\
\hline & 5 & 6800.03 & 2920 & 0.06 & 6800.06 & 2810 & 0.06 & 6774.04 & 3080 & 0.44 \\
\hline \multirow{5}{*}{$\mathrm{S}_{4}$} & 1 & 849.59 & 2510 & 0.08 & 849.57 & 3520 & 0.08 & 849.62 & 3060 & 0.08 \\
\hline & 2 & 1144.30 & 390 & 0.06 & 1144.78 & 3580 & 0.02 & 1144.92 & 1810 & 0.00 \\
\hline & 3 & 2964.82 & 3390 & 0.02 & 2964.85 & 583 & 0.02 & 2965.12 & 670 & 0.01 \\
\hline & 4 & 3066.76 & 580 & 0.00 & 3066.80 & 310 & 0.00 & 3066.78 & 58 & 0.00 \\
\hline & 5 & 6799.83 & 2690 & 0.07 & 6799.15 & 1890 & 0.08 & 6801.37 & 2410 & 0.05 \\
\hline \multirow{5}{*}{$\mathrm{S}_{5}$} & 1 & 849.93 & 1410 & 0.05 & 850.11 & 1900 & 0.02 & 850.08 & 3105 & 0.03 \\
\hline & 2 & 1144.16 & 1320 & 0.00 & 1144.20 & 1580 & 0.00 & 1144.24 & 354 & 0.00 \\
\hline & 3 & 2964.83 & 2880 & 0.02 & 2964.80 & 170 & 0.02 & 2965.08 & 190 & 0.01 \\
\hline & 4 & 3066.64 & 36 & 0.00 & 3066.56 & 44 & 0.00 & 3066.64 & 25 & 0.00 \\
\hline & 5 & 6785.81 & 1710 & 0.20 & 6797.22 & 1960 & 0.03 & 6795.73 & 3560 & 0.06 \\
\hline \multirow{5}{*}{$\mathrm{S}_{6}$} & 1 & 872.06 & 410 & 0.00 & 872.13 & 2420 & 0.01 & 872.05 & 1891 & 0.01 \\
\hline & 2 & 1187.44 & 52 & 0.00 & 1187.34 & 158 & 0.00 & 1187.38 & 1051 & 0.00 \\
\hline & 3 & 2919.97 & 2800 & 0.00 & 2920.90 & 60 & 0.00 & 2920.11 & 1550 & 0.00 \\
\hline & 4 & 3028.38 & 80 & 0.00 & 3028.24 & 23 & 0.00 & 3028.28 & 17 & 0.00 \\
\hline & 5 & 6721.14 & 560 & 0.03 & 6721.77 & 2150 & 0.02 & 6721.42 & 480 & 0.02 \\
\hline
\end{tabular}

the difference of the weights in the aft and fore parts should be within the longitudinal equilibrium. Since the expressions in the absolute values in (13) and (14) are linear, and since the RHS of both constraint sets are constant, each of the constraint sets are equivalent with two sets of linear constraints.

Constraints (15) - (18) compute values for some of the variables in the objective function. Constraint set (15) sets the binary variables $\delta_{p l}$ to 1 if there are containers to be handled in port $p$ in the location below a given on-deck location $l$. Constraint (16) then calculates the number of hatch over-stow containers in on-deck location $l$ in port $p$.
Crane makespan is the amount of time needed for the cranes to perform all loading and unloading operations, this is calculated by constraint set (17). In the Cargo Mix Problem, stacking rules are not taken explicitly into account. For this reason, some Slot Planning instances may be infeasible. A possible source of infeasibility is reefer containers, since they can only be stowed in slots with power plugs, which might be occupied by other container types. This is handled by reducing the capacity of reefer containers in a location by a proportional factor $F_{p l}^{t}$, where $F_{p l}^{t}=\frac{C_{p l}^{R}}{C_{p l}^{T}}$ for all non-reefer containers and a factor 1 for all 
Table 9 CMP results with different optimality gaps. For each gap, the table shows the optimality gap and the run time. A 0.00 in the Gap column means that the default Gurobi optimality gap of $0.01 \%$ or less was reached. The values for $Q_{T}$ and $Q_{L}$ are the same as their values in Table 7

\begin{tabular}{|c|c|c|c|c|c|c|c|}
\hline \multirow[t]{2}{*}{ Scen } & \multirow[t]{2}{*}{ ID } & \multicolumn{2}{|c|}{$1 \% \mathrm{Gap}$} & \multicolumn{2}{|c|}{$0.5 \%$ Gap } & \multicolumn{2}{|c|}{$0.1 \% \mathrm{Gap}$} \\
\hline & & Gap (\%) & Time (s) & Gap (\%) & Time (s) & Gap (\%) & Time (s) \\
\hline \multirow{5}{*}{$\mathrm{S}_{1}$} & 1 & 0.79 & 100 & 0.43 & 135 & - & - \\
\hline & 2 & 0.84 & 66 & 0.25 & 320 & 0.10 & 710 \\
\hline & 3 & 0.83 & 60 & 0.02 & 350 & 0.02 & 350 \\
\hline & 4 & 0.76 & 160 & 0.01 & 570 & 0.01 & 570 \\
\hline & 5 & 0.51 & 1830 & 0.29 & 2380 & - & - \\
\hline \multirow{5}{*}{$\mathrm{S}_{2}$} & 1 & 0.96 & 111 & 0.42 & 335 & - & - \\
\hline & 2 & 0.23 & 305 & 0.23 & 305 & 0.06 & 535 \\
\hline & 3 & 0.21 & 350 & 0.21 & 350 & 0.04 & 1950 \\
\hline & 4 & 0.89 & 72 & 0.01 & 285 & 0.01 & 285 \\
\hline & 5 & 0.73 & 2522 & 0.46 & 2524 & - & - \\
\hline \multirow{5}{*}{$\mathrm{S}_{3}$} & 1 & 0.95 & 62 & 0.45 & 193 & - & - \\
\hline & 2 & 0.43 & 238 & 0.43 & 238 & 0.10 & 2582 \\
\hline & 3 & 0.51 & 107 & 0.08 & 450 & 0.08 & 450 \\
\hline & 4 & 0.50 & 41 & 0.50 & 41 & 0.08 & 441 \\
\hline & 5 & 0.38 & 364 & 0.38 & 364 & 0.10 & 859 \\
\hline \multirow{5}{*}{$\mathrm{S}_{4}$} & 1 & 0.79 & 41 & 0.36 & 66 & 0.10 & 2690 \\
\hline & 2 & 0.47 & 103 & 0.47 & 103 & 0.05 & 151 \\
\hline & 3 & 0.91 & 50 & 0.11 & 170 & 0.06 & 340 \\
\hline & 4 & 0.14 & 77 & 0.14 & 77 & 0.00 & 376 \\
\hline & 5 & 0.53 & 583 & 0.23 & 747 & 0.06 & 2707 \\
\hline \multirow{5}{*}{$\mathrm{S}_{5}$} & 1 & 0.67 & 14 & 0.46 & 19 & 0.10 & 1570 \\
\hline & 2 & 0.08 & 44 & 0.08 & 44 & 0.08 & 44 \\
\hline & 3 & 0.71 & 65 & 0.19 & 143 & 0.03 & 189 \\
\hline & 4 & 0.01 & 35 & 0.01 & 35 & 0.01 & 35 \\
\hline & 5 & 0.96 & 239 & 0.17 & 369 & 0.10 & 725 \\
\hline \multirow{5}{*}{$\mathrm{S}_{6}$} & 1 & 0.56 & 7 & 0.43 & 9 & 0.09 & 309 \\
\hline & 2 & 0.09 & 9 & 0.09 & 9 & 0.09 & 9 \\
\hline & 3 & 0.04 & 41 & 0.04 & 41 & 0.04 & 41 \\
\hline & 4 & 0.01 & 27 & 0.01 & 27 & 0.01 & 27 \\
\hline & 5 & 0.92 & 57 & 0.05 & 153 & 0.05 & 153 \\
\hline
\end{tabular}

reefer containers. Constraints (18) set the values for the variables $y_{p l}^{R}$, i.e., the reduction of the capacity of reefer containers within locations, which makes stowing non-reefer containers in reefer slots more costly.

Finally, constraints (19) - (25) give domains for the variables.

The mathematical formulation and the short explanation given here may be a bit hard to read and understand. A less formal and more understandable description of the objective and the constraints can be found in Section 2.2.

\section{Computational results}

In this section, we present the results from our computational experiments. Neither industrial contacts nor other researchers have been able or willing to share instances with us, so we have generated random instances, which we believe correspond closely to real world scenarios for the CMP related to container ships with capacities from 2376 to 18032 TEUs.

An overview of the considered container ships are reported in Table 6, in the columns under vessels.

The container demand has been randomly generated such that for each transport (origin-destination), there should be 
a positive demand for standard, reefer, and IMO containers. In particular, six scenarios with different percentages of standard $(\mathrm{S})$, reefer $(\mathrm{R})$ and four classes of IMO (IMOC $, \mathrm{IMOC}_{2}, \mathrm{IMOC}_{3}$, $\mathrm{IMOC}_{4}$ ) containers have been generated as listed in Table 5.

The weight classes we use for both $20^{\prime}$ and $40^{\prime}$ containers are the same as the weight classes used in [6]. In [6], containers of length 40 ' belong to light, medium and heavy classes corresponding to weights of 10, 20 and 30 tons, respectively, whereas the same classes are associated with 7,14 and 21 tons for 20' containers.

We assume that the considered route has six ports, and, for each origin port, the possible destinations will be all downstream ports.

The proposed model was implemented in Pyomo [20] and solved with the MIP solver Gurobi 7.50 [21]. All the tests were executed on a Linux machine with Intel Core i7-5600U, CPU $2.60 \mathrm{GHz} \times 4$ and $16 \mathrm{~GB}$ of memory, no parallelism was used. In the tests reported in Table 7, all instances have been solved by considering the transversal equilibrium $\left(Q_{L}\right)$ and longitudinal equilibrium $\left(\mathrm{Q}_{\mathrm{T}}\right)$ of 60 tons (equivalent to two $40^{\prime}$ heavy containers). A time limit of one hour has been assigned to the solver. As shown in Table 7, 13 instances are solved to optimality with the default Gurobi optimality gap of $0.01 \%$. The remaining instances are solved with an optimality gap of less than $0.5 \%$. In particular, 12 of the instances are solved with an optimality gap less than or equal to $0.1 \%$, and the remaining five instances, which belong to Scenario $\mathrm{S}_{1}$ (containing six container types and following all principles) and $\mathrm{S}_{2}$ (containing five container types and following all principles) are solved with an optimality gap greater than $0.1 \%$, but less than or equal to $0.5 \%$. As expected, Scenario $\mathrm{S}_{1}$ and $\mathrm{S}_{2}$ seems to be more difficult to solve, whereas $\mathrm{S}_{6}$ (containing only standard containers) is easy to solve.

In order to evaluate the robustness of the model, we tested with different values for transversal $\left(\mathrm{Q}_{\mathrm{L}}\right)$ and longitudinal $\left(\mathrm{Q}_{\mathrm{L}}\right)$ equilibriums, ranging from 30 to 120 tons. As can be seen from
Table 8 , most of the instances are solved with an optimality gap less than $0.1 \%$, the remaining instances are solved with an optimality gap less than $1 \%$ within the time limit.

Finally, we have run the instances with larger optimality gaps to see how long time is needed to find a solution within the given gap, and how good this solution is compared to the "true" optimal solution. The results of these runs are given in Table 9 . As expected, the run times decrease with increasing optimality gaps. With an optimality gap of $1 \%$ or $0.5 \%$, almost all instances are solved within ten minutes (only two instances needed more than ten minutes with the given gaps). With $0.1 \%$ optimality gap, 17 instances are solved in less than ten minutes, but five instances are not solved with the given gap within one hour.

The results show that by increasing optimality gaps, the solution times can be brought down to quite acceptable levels without giving away much in terms of solution quality. Which gap to use and which amount of time to be regarded as "reasonable time" will depend on the situation, this has to be decided by the problem owner who is going to use the solution for planning.

\section{Conclusions}

This paper considers the Cargo Mix Problem (CMP), which is an important optimization problem in liner shipping, particularly for the efficiency of loading and unloading of container ships. We have extended existing models for the CMP by including IMO containers holding dangerous goods.

The proposed model was implemented in Pyomo and solved with Gurobi 7.5 for 30 instances with four different transversal and longitudinal equilibriums. The computational experiments show that our model can be solved to optimality or near optimality in reasonable time using a standard MIP solver.

\section{References}

[1] DELGADO, A. Models and algorithms for container vessel stowage optimization. PhD thesis, University of Copenhagen, 2013.

[2] CHRISTENSEN, J., PACINO, D. A matheuristic for the Cargo Mix Problem with Block Stowage. Transportation Research Part E: Logistics and Transportation Review [online]. 2017, 97, p. 151-171. ISSN 1366-5545/e ISSN 1878-5794. Available from: https://doi. $\operatorname{org} / 10.1016 / j$.tre.2016.10.005

[3] FAN, L., et al. Stowage planning of large containership with tradeoff between crane workload balance and ship stability. International MultiConference of Engineers and Computers Scientists : proceedings [online]. Vol. III. 2010. ISBN 978-988-18210-5-8/ISSN 20780958/eISSN 2078-0966, p. 1-7. Available from: http://www.iaeng.org/publication/IMECS2010/IMECS2010_pp1537-1543.pdf

[4] PACINO, D., et al. Fast generation of near-optimal plans for eco-efficient stowage of large container vessels. 2nd International Joint Conference on Artificial Intelligence : proceedings. 2011. ISSN 1045-0823, p. 286-301.

[5] PACINO, D., et al. An accurate model for seaworthy container vessel stowage planning with ballast tanks. 3rd International Conference on Computational Logistics : proceedings [online]. Springer, Berlin, Heidelberg, 2012. ISBN 978-3-642-33586-0/eISBN 978-3-642-33587-7, p. 17-32. Available from: https://doi.org/10.1007/978-3-642-33587-7_2

[6] AMBrosinO, D., PAOLUCCI, M., SCIOMACHEN, A. Computational evaluation of a MIP model for multi-port stowage planning problems. Soft Computing [online]. 2017, 21(7), p. 1753-1763. ISSN 1432-7643/eISSN 1433-7479. Available from: https:// doi.org/10.1007/s00500-015-1879-y

[7] AMBROSINO, D., SCIOMACHEN, A. Using a bin packing approach for stowing hazardous containers into containerships. In: FASANO, G., PINTER, J. D. (eds.) Optimized packings with applications [online]. Springer Optimization and Its Applications 105. Springer, Cham. 2015, 5, p. 1-18. eISBN 978-3-319-18899-7/ISSN 1931-6828. Available from: https://doi.org/10.1007/978-3-31918899-7_12 
[8] International Maritime Organization. International Maritime Dangerous Goods code [online]. Vol. 1. London: Polestar Wheatons Ltd, 2006. ISBN 978-92-801-4214-3. Available from: https://law.resource.org/pub/us/cfr/ibr/004/imo.imdg.1.2006.pdf

[9] AMBrosinO, D., SCIOMACHEN, A., TANFANI, E. Stowing a containership: the master bay plan problem. Transportation Research Part A: Policy and Practice [online]. 2004, 38(2), p. 81-99. ISSN 0965-8564/eISSN 1879-2375. Available from: https://doi.org/10.1016/j.tra.2003.09.002

[10] AMBROSINO, D., et al. Modelling the multi-port master bay problem. In: Dauer, R. R. M., Sagarra, R. M., de Oses, F. X. M (eds.): Maritime Transport IV. UPC (Universititat Politecnica de Catalunya), Barcelona, 2009. p. 63-73.

[11] AMBROSINO, D., PAOLUCCI, M., SCIOMACHEN, A. Experimental evaluation of mixed integer programming models for the multi-port master bay plan problem. Flexible Services and Manufacturing Journal [online]. 2015, 27(2-3), p. 263-284. ISSN 19366582/eISSN 1936-6590. Available from: https://doi.org/10.1007/s10696-013-9185-4

[12] LI, F., et al. An Integer linear programming for container stowage problem. In: International Conference on Computational Science : proceedings. Lecture Notes in Computer Science, vol 5101 [online]. Springer, Berlin, Heidelberg, 2008. ISBN 978-3-540-69383-3/ eISBN 978-3-540-69384-0, p. 853-862. Available from: https://doi.org/10.1007/978-3-540-69384-0_90

[13] DING, D., CHOU, M. C. Stowage planning for container ships: A heuristic algorithm to reduce the number of shifts. European Journal of Operational Research [online]. 2015, 246(1), p. 242-249. ISSN 0377-2217. Available from: https://doi.org/10.1016/j. ejor.2015.03.044

[14] WILSON, I. D., ROACH, P. A. Container stowage planning: a methodology for generating computerised solutions. Journal of the Operational Research Society [online]. 2000, 51(11), p. 1248-1255. ISSN 0160-5682/e ISSN 1476-9360. Available from: https://doi. org/10.1057/palgrave.jors.2601022

[15] WILSON, I. D., ROACH, P. A., WARE, J. A. Container stowage pre-planning: using search to generate solutions, a case study. Knowledge-Based Systems [online]. 2001, 14(3-4), p. 137-145. ISSN 0950-7051/eISSN 1872-7409. Available from: https://doi. org/10.1016/S0950-7051(01)00090-9

[16] KANG, J-G., KIM, Y-D. Stowage planning in maritime container transportation. Journal of the Operational Research Society [online]. 2002, 53(4), p. 415-426. ISSN 0160-5682. Available from: https://doi.org/10.1057/palgrave.jors.2601322

[17] WEI-YING, Z., YAN, L., ZHUO-SHANG, J. Model and algorithm for container ship stowage planning based on bin-packing problem. Journal of Marine Science and application [online]. 2005, 4(3), p. 30-36. ISSN 1671-9433/eISSN 1993-5048. Available from: https://doi.org/10.1007/s11804-005-0018-z

[18] AZEVEDO, A. T., et al. Solution of the 3D stochastic stowage planning for container ships through representation by rules. Fourth International Workshop on Knowledge Discovery, Knowledge Management and Decision Support : proceedings [online]. Atlantis Press. 2013. ISBN 978-90-78677-86-4/ISSN 1951-6851. Available from: https://doi.org/10.2991/.2013.15

[19] PARRENO, F., PACINO, D., ALVAREZ-VALDES, R. A GRASP algorithm for the container stowage slot planning problem. Transportation Research Part E: Logistics and Transportation Review [online]. 2016, 94, p. 141-157. ISSN 1366-5545/eISSN 1878 5794. Available from: https://doi.org/10.1016/j.tre.2016.07.011

[20] Pyomo [online]. Available from: www.pyomo.org

[21] MIP solver Gurobi [online]. Available from: www.gurobi.com 